\title{
The Perspective of Balancing the Economic Growth of Healthcare Systems and Environmental Prevention:
} The Efficient Budget for ASEAN-3 Countries

\author{
Anuphak Saosaovaphak, Chiang Mai University, Thailand \\ Chukiat Chaiboonsri, Chiang Mai University, Thailand \\ Satawat O. Wannapan, Chiang Mai University, Thailand
}

\begin{abstract}
Based on real situations that mankind is confronting with the difficult era, insufficiency in food supplies, natural disasters, epidemic, etc., the paper is to econometrically compute portfolio optimization and predict efficiency frontiers for solving the most sensible scenario to suggest a sustainable policy in the three important pillars such as the growth of economic systems, environmental management, and public healthcare. The main observations are annual time-series information between 2000 and 2017 collected from three countries in ASEAN. Singapore, Thailand, and Malaysia are the targets. Methodologically, this research applies the quantum mechanism and the wave function for clarifying a real data distribution, true mean, and standard deviation of the data. These outcomes are the initial raw material for the modern portfolio optimization (for short-run policies) and efficient frontier computation (for long-term policies). Empirically, the results show some exclusive issues that can help in managing feasible budget allocations fairly and sustainably.
\end{abstract}

\section{KEYWORDS}

ASEAN Countries, Economic Growth, Efficiency Frontier, Environment, Modern Portfolio Optimization, Public Healthcare, Quantum Mechanics, Sustainability, Wave Function

\section{INTRODUCTION}

It is undeniable to state that this era is the age of super-high technologies. Globalization has been now making people become untouchable since the world is continuously smaller by wireless networks. They are connected always with micro technologies in small devices, especially smart phones. They want to reach the sky; they can do it by overcoming aerodynamics. They want to skill their juvenile; they try to cheat the skin and body by unethical augmentation. Even they want to conquer the planet; they have done it by vastly using and consuming natural resources to satisfy their eagerness. Interestingly, if nothing they plan to do will be impossible for them, why the chronicle struggles such as economic collapses, rumor wars, natural disasters, even epidemic every 100 years still threaten this kind of the great living creature, which is created from dust.

It has been several years that humans are struggling to overwhelm the nature cycle. As Figure 1, deforestation has been appeared during 1990 to 2016, and this trend is seemingly unstoppable. 
People have seized benefits from forests, but the restoration has not been consciously realized. The unflavored sequence was detected in 2003, scientists and the world were awakening on the ability of coronaviruses for animal-to-human transmission. It was obviously one of the worst epidemics in humankind's history (Lau \& Chan, 2015). The trace was back to the wildlife market in China as the intermediate host (Lau et al, 2005; Ge, 2013). In 2019, the consequent has been far worst. The new coronavirus stated by (Hoek, 2004), which is yet difficult to control its rapid spreads, is not a new issue, but it is ignored. Figure 2 and 3 are the evidences. The rocketed exponential graphs are the great failure in the world healthcare history. Is the cause from the advance of civilization, or natural revolution? This question seems to be far from decisively making the answer. However, it is inevitable that humans are dragged into the charge of attempted response victims.

Figure 1. The trend of world forest area (sq.km)

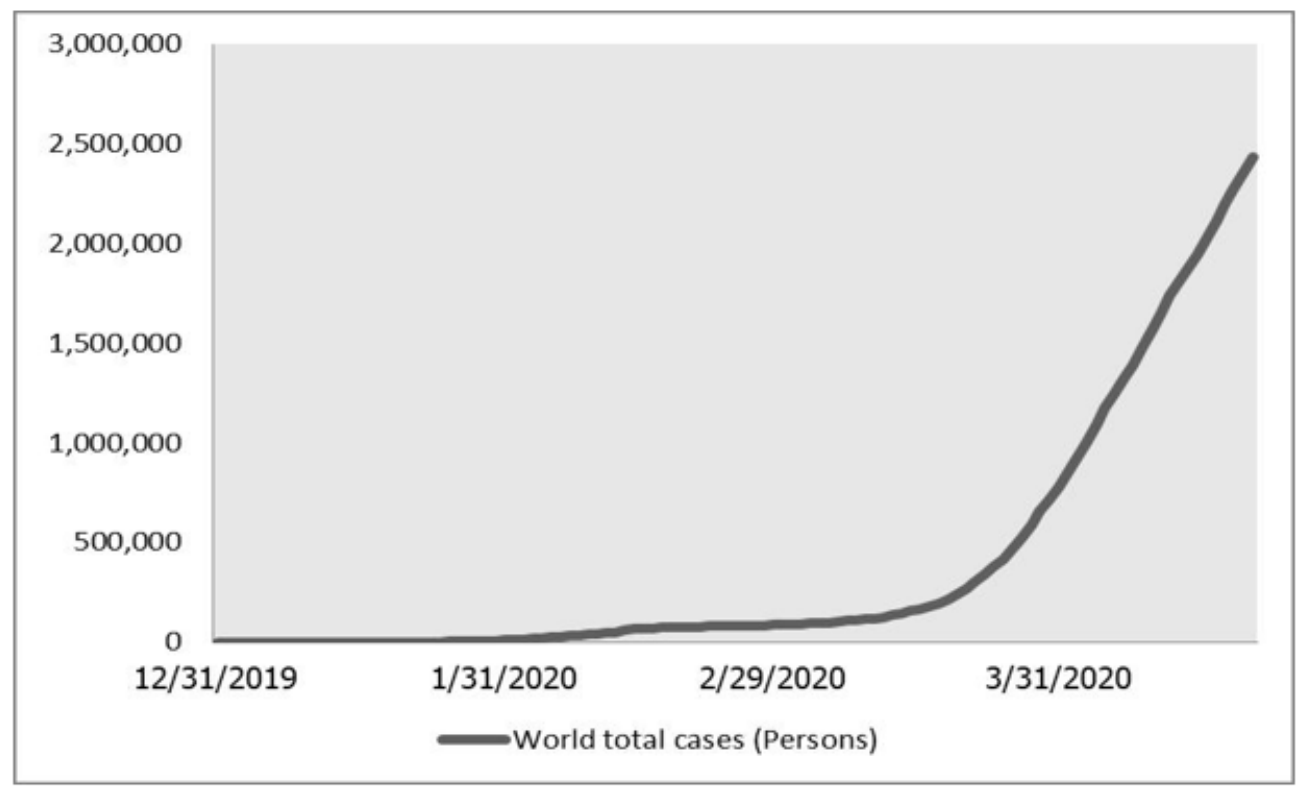

Source: World Bank Database (https://data.worldbank.org/indicator/AG.LND.FRST.ZS.) 
Figure 2. The number of Coronavirus (COVID-19) cases

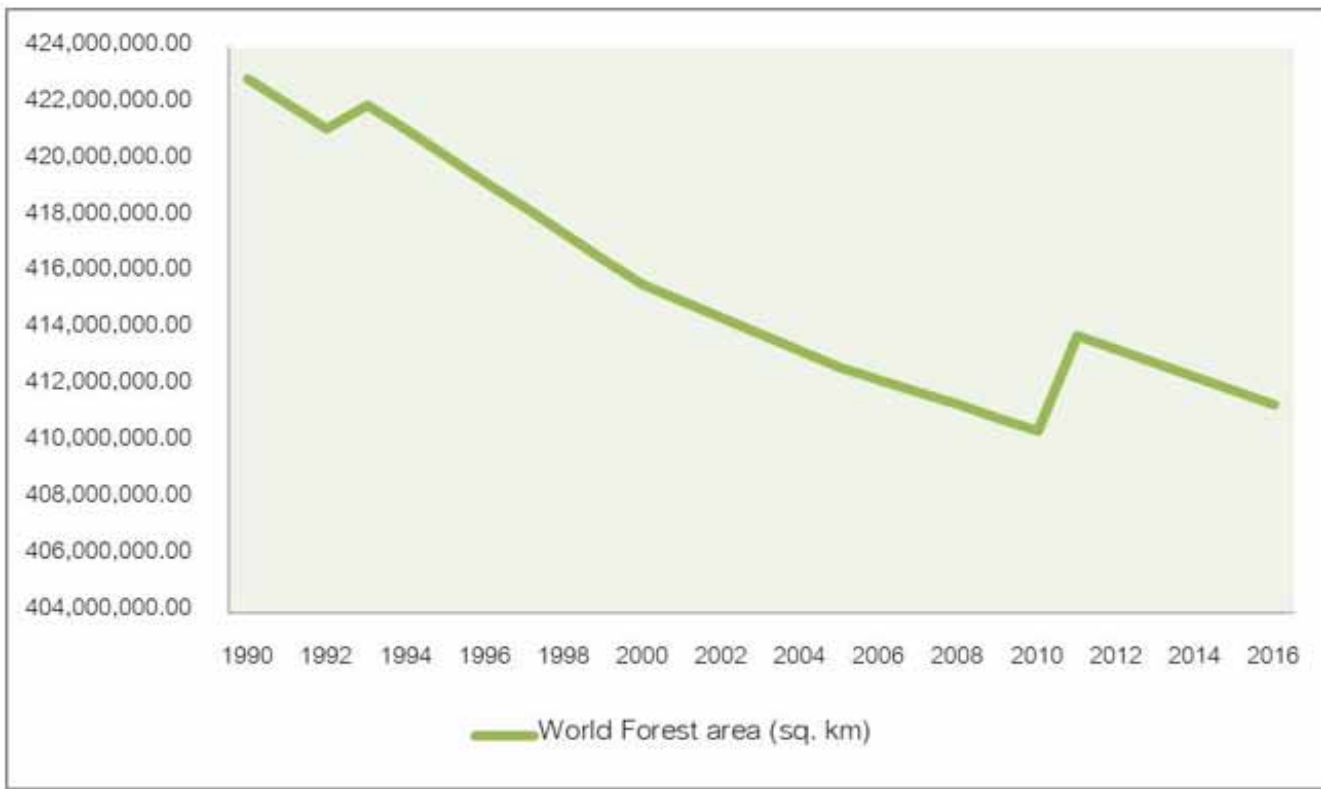

Source: Global Change Data Lab (https://ourworldindata.org/covid-cases.)

Figure 3. The number of deaths causing by COVID-19

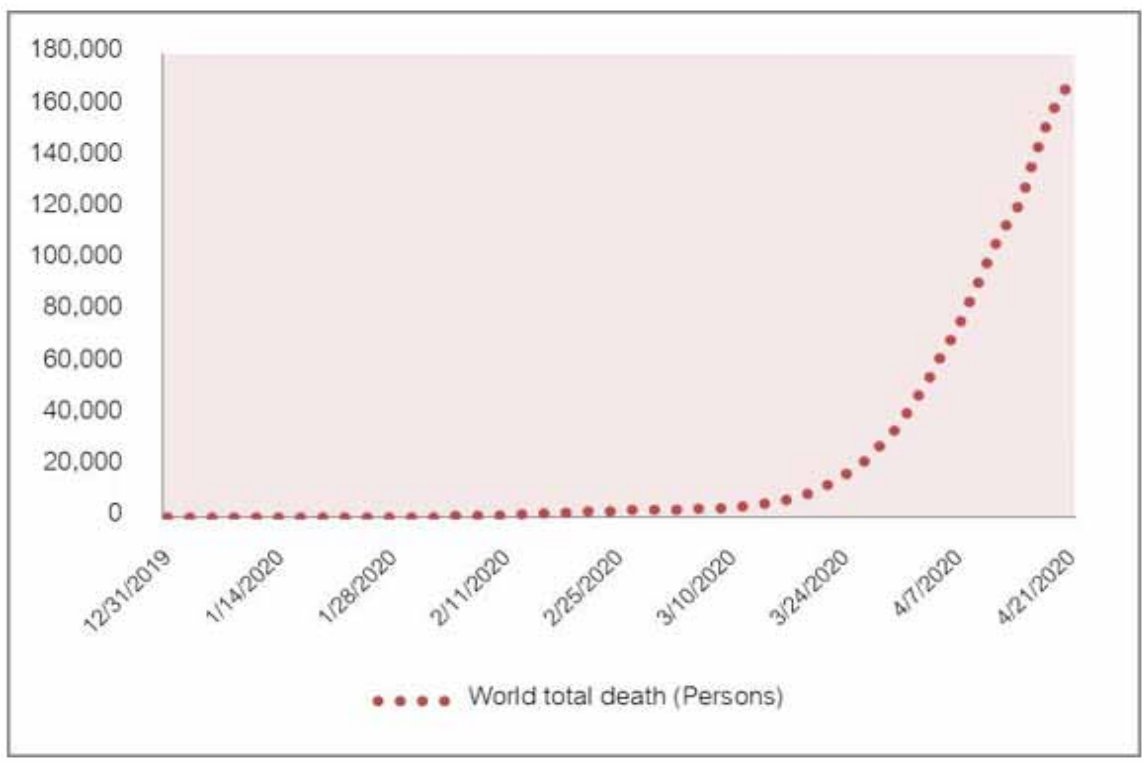

Source: Global Change Data Lab (https://ourworldindata.org/covid-cases.) 
Although natural disturbances by people cause the uncontrollable epidemic of Coronavirus, the more chronicle trouble is behind the epidemical timeline. Unfortunately, the crisis has already transformed into an economic and labor market shock, impacting not only supplies (production of goods and services) but also demands (national and international consumption and investment). An enormous number of unemployed labors is inevitable. Moreover, the economic shutdown causes the problem of over-supplies to the energy sector, especially future markets. This ineffective resource allocation will consequently bring ecosystems to fall disorderly. Furthermore, social-welfare and healthcare collapses are sequence. This will be a huge challenge for policy makers to properly optimize budget constraints during a short-run period and long-term adjustment.

As the perspective to econometrically find a solution, to address these unfavorable crises crucially needs punctilious informational details. Distributions are indeed the key to solve this complexity. Statistically, a good distribution is one that is just or sensible, or at least one in which the degree of inequality is restricted within some acceptable ranges (Daly (2004), Gherasim \& Gherasim (2016)). Economically, the distribution in the modern economy is driven by both the increment and diversification of supplies and demands of goods and the increasing consumer's demands across the quality and efficiency required for their manufacture (Piketty, 2015). Educationally, the word "distribution" is a scope through which statisticians observe the variation in data is developed (Wild, 2015). Thus, in the common sense, the distributions such as normal or weighted distributions, or others are milestone for efficient modeling of statistical data and prediction when standard distributions are not appropriate (Saghir et al, 2017).

For reality, it is nearly impossible to decisively state that our observed data is normal; statistically meaning it automatically contains the condition of the asymptotic movement in its detail frequencies. Interestingly, a normal distribution exists by assumptions, but assumptions generate a paranormal distribution. With this controversy, it looks suspicious if the normal distribution is used to be the vital part of the model which is aimed to clarify the complexity of uncontrollable situations such as environmental problems, epidemic, or even economic depression.

What is the way out? This paper is the introduction of the wave function to solve an econometric optimizing model through generating a novel distributional data for providing feasible resource allocations, the most difficult task for economists and econometricians. The former, the wave function, is a measurement on a single quantum system which determines the expectation values of (not necessarily commuting) observations while the wave function is protected from collapsing because it undergoes another suitably chosen interaction (Aharonov et al, 1993). The physical meaning of the wave function is a crucial interpretative problem of quantum mechanics (Gao, 2013), and the simulation of quantum computing is a huge challenge for econometric estimations and predictions. Although there are questions regarding the ability of the wave function to explain real distribution (Jung, 2011), the Schrodinger wave equation is seemingly the best guess of how nature behaves. This complexity needs a neat interpretation in quantum mechanics. It is a novel way to conduct uncertainty analysis based on a new calculus of probabilities, which is the way to do econometrics (Nguyen \& Dong, 2018). In the current moment, the cutting-edge applications of quantum field theory and quantum information theory are descriptively applied for an economics exploration by Patra (2019). Quantum computing trends to be the evolution for finance economics. Orrell (2020) applies a quantum walk model to explore key aspects of investor behaviors who stand on options in financial markets. Additionally, Orrell (2020) have done a quantum approach to economics, security and international relations. Ultimately, by following literatures, the main purpose of the paper is to optimize the short-run and long-run scenarios, which can provide sensible solutions for sustainability in economics, natural resource management, and healthcare by using portfolio optimization and efficiency frontiers. Quantum data distributions are implied to be the key that contributes the "real distribution" for real quantitative economics researches. 


\section{LITERATURE REVIEW}

Before computational outcomes are clarified and visualized, the pillar of the paper is constructed by relying on the three theoretical frameworks. In other words, the idea starts at the welfare society is the root main concept to shift up the level of budget efficiencies. Consequently, the aspect of feasible allocation is applied to back up the appearance of welfare economics. The feasible budget allocation is implemented by employing the concept of the economic optimization. The three connected ideas are literally explained as follows:

\subsection{The Concept of Welfare Economics}

Welfare economics is the vital part of the general body of economic theory, which is inevitably related to policy implementation (Scitovsky, 1951). Dealing with some social objective, a rank ordering of social preferences, and the ethical concept, value adjustments are the essential component for the process to find the shape of the social welfare function (Hébert \& Ekelund, 1984). With this complexity, the concept of welfare economy is about an indefinite number of different possible optimal values, distinguished from one another by differences in the distribution of social wealth (Hicks, 1939). In modern world, the notation of welfare economy does not have only the shift of living standard, but it contains two crucial ingredients; welfare and sustainability. In other words, the coincidence of satisfaction of needs and aspirations with really achieved ones relates to the notation of social happiness. However, the process to satisfy

people' needs is not complete if a sustainably feasible resource allocation is not recognized as a long-term policy (Ivankina \& Latygovskaya, 2015). The welfare society is still issued among globalization. Nanni (2016) stated a query regarding the choice between a "well-being" personal concept and "welfare-society" economics. the historical process can be the answer as a communicative process that brings response reactions on the part of the social recipient or of any of the various stakeholders. Hernawan (2017) gave a solution which implies the role of regional council in carrying out its legislative function implemented through the process of making policy on public welfare. Koo et al, (2019) descriptively argued that unbalancing welfare societies can harness a country's innovative potential and contribute to the country's long-term growth. Khasandy and Badrudin (2019) made a conclusion that domestic systems can play a vital role in supporting sustainable economic development and facilitating better financial inclusion. Since the limitation of resources is recently becoming more evident but the maximization of preferences is inevitable. Sustainable wealth distributions are the key issue mentioning in this paper.

To study a practical application, welfare economics consists in setting an initial ideal for resource weights. As seen in the contribution of Alvarez et al (2017), the portfolios for all resource management are ideally utilized by setting an equal to 1 . The reason is clear where environmental portfolios are mentioned and optimized in separation, careful consideration should be made when biophysical units are implied as portfolio weights to aggregate relative outcomes for various assets (Matthies et al, 2019). This idea is crucial for feasible allocations, especially environmental issues intertwine with economic growth and healthcare.

\subsection{Feasible Allocation in Economics}

A feasible allocation is Pareto optimal (alternatively called Pareto efficient) if there is no other feasible allocation that makes at least one of the agents in an economy which is strictly better off without making someone else worse off (a win-win situation) (Tsoulouhas, 2014). The feasible allocation, in other words, is weakly Pareto optimal if other feasible allocation that assembles all the agents in an economy strictly better off does not exit. The word allocation is a clear definition meaning the values or volumes that each goods each agent will gain. When an allocation is "feasible", it implies that the total amount of goods is efficiently provided to agents and this distribution does not exceed the total available number of resources in the economy (Tsoulouhas, 2014). 
Pareto efficiency is a very useful concept when considering policy implementation. It leads economists to make a distinction to those agents crucial to avoid outcomes that are undesirable by any preference measurement versus agent interventions that are desirable only if some individuals are esteemed more deserving than others (Phelan \& Rustichini, 2018). From a positive point of view, Pareto outcomes are frequently mentioned as a benchmark-result that expects to occur although information is incomplete or elusive private. Many mechanisms and market-type mechanisms have been proposed to implement Pareto optimal allocations or social distributions, the Pareto efficient correspondence can be totally implemented by an incentive compatible mechanism such as an optimization. The Pareto optimization is literally mentioned in various types of academic researches, for instance, Tian (2009), Dold \& Krieger (2017), Mendolicchio \& Pietra (2018), Stuart et al, (2019), and Biró \& Gudmundsson (2020).

Practically, the feasible allocation concept helps to clarify a reasonable resource portfolio. Based on the basic investment weight, equal terms are conceptually simple, but they are suspicious. Uncertainties are the key factor that influences a vary allocation. The two different branch researches confirm this conclusion. Tóth et al (2016) stated the development of risk and return between crop farms and animal farms caused the unbalance allocation in Slovak agriculture. On the other hand, Ando et al (2018) explained from their contribution that great uncertainties in climate changes caused different weights in ecological outcomes. Hence, this can be implied that the feasible budget allocation in each country is predicted to be dissimilar portions.

\subsection{Economic Optimization}

For practically suggesting the policy of wealth distributions, feasible allocations need strategic optimization models, which are characterized by a few salient features. The optimization process contains inherently long-term planning horizons and intrinsic correlations between process variables (such as technical capacity and productivity) and economic parameters such as incomes, costs, surplus, volumes, and values (Geraili et al, 2013). Interestingly, the model can handle linear and non-linear functions, and it gives an optimal duration and the resource usages are leveled economically (Karshenas $\&$ Haber, 2006). This is useful when researchers need to mathematically solve complex objects such as a mixed integer programming model, decision-making analysis, or portfolio optimization in the various research types, including sustainable energy, biodiversity, forest biomass, even cost-benefit analyzing for pollution effects (Zamora-Cristales et al, 2015, Dobrovolskiene \& Tamošiunien, 2016, Fang et al, (2016), Mohajan, 2017, Mineyama (2019), and Wang \& Lu (2019)). For recently applying to this paper, the optimizing process is the tool to solve weighted portions for managing budget allocations in three pillars of country development such as economic expansions, environmental restorations, and healthcare supports.

\section{THEORY AND METHODOLOGY}

Methodologically, the computational session is divided into three phrases. Firstly, quantum mechanics and simulations applying to compute the wave function is the novel way to visualize the distribution of observed data. Secondly, the means and standard errors obtained from the wave distribution are employed to investigate the short-term scenarios for budget allocations by using the optimization model on Markowitz theory. Lastly, the long-term efficiency frontiers of feasible allocations are provided for recommending fiscal policies solutions for countries' sustainable development.

\subsection{Quantum Mechanics Applying for a Novel Data Distribution}

Towards Einstein (1905) and De-Broglie (1924) suggest that e - (electron) has dual characters which it can behave as a wave as well as a particle combinatory. Einstein (1905) tried to describe that $E$ $=M C^{2}$ for particle behaviors. Also, De-Broglie (1924) gives an explanation that the formula which describes the wave is given by $\mathrm{E}=h v$. Mathematically, the equation (1) is utilized to calculate the 
wavelength of the proton $\left(\mathrm{e}^{+}\right)$which is the vital part of quantum mechanics in modern physics, and it is expressed as follows

$$
\lambda=\frac{h}{p} .
$$

And define that $\lambda=$ wavelength, $h=$ Planck constant, $p=$ momentum for the calculation of wavelength of the proton. However, the quantum mechanics not be able to distinction between wave and particle by easy way. Therefore, the physicist attempted to understand and measure those of them by wave function for an explanation the real distribution or continuous probability densities of data analysis system (Thompson, 2018). Normally, the wave function originally was developed by Schrödinger (1926). He developed the wave function in 1925 to describes the state function of a quantum mechanical system (see more detail in equation (2))

$$
\boldsymbol{H}(\boldsymbol{t})|\grave{E}(\boldsymbol{t})\rangle=\boldsymbol{i} \hbar \frac{\partial}{\partial \boldsymbol{t}} \grave{\boldsymbol{E}}(\boldsymbol{t})>
$$

This equation is named as the Schrödinger equation and the $H(\mathrm{t})$ is the Hamiltonian operator (state of the system). Moreover, $\psi(\mathrm{t})$ is the wave function and $\mathrm{h}$ is the reduced Planck constant. $i$ is the imaginary unit. From the equation (2), this is the time-dependent Schrödinger formula. However, Thompson (2018) suggests that real-world data without modification may be explored by Schrödinger equation which it is more realistic than only assuming of the normal distribution for those of data before go to step of estimation. Thomson and team explain that $\mathrm{H}_{\mathrm{N}}$ is the Hermite polynomial degree n. This can be more clearly expressed by

$$
\boldsymbol{h}_{\boldsymbol{n}}(\boldsymbol{x})=\boldsymbol{H}_{\boldsymbol{n}}(\boldsymbol{x}) \frac{\boldsymbol{e}^{-\boldsymbol{x}^{2} / 2}}{\left(\sqrt{\grave{A}} 2^{n} n !\right)^{1 / 2}}
$$

\section{Define:}

$\boldsymbol{H}_{\boldsymbol{n}}=$ physicists' Hermite polynomial of degree $n$

$x=$ all secondary data were implemented in this research such as GDP, Energy

Consumption (ec), Carbon footprints (Co2), and Healthcare expenditure

(hp) of Thailand, Malaysian, and Singapore respectively.

From the equation (3), one of main purposes in this paper is to compute the real distribution for all observed data based on the Schrödinger wave function (Schrödinger, 1926). to yield with unseen influenced details inside the seeing observable distribution. In addition, the orthonormality of Hermite polynomials is given by the equation (4) as the expression below:

Choosing the maximum degree $K$ then received the equation (5) below

$$
\omega_{k}=\int_{-\infty}^{\infty} h_{k}(x) \sqrt{f(x)} d x
$$




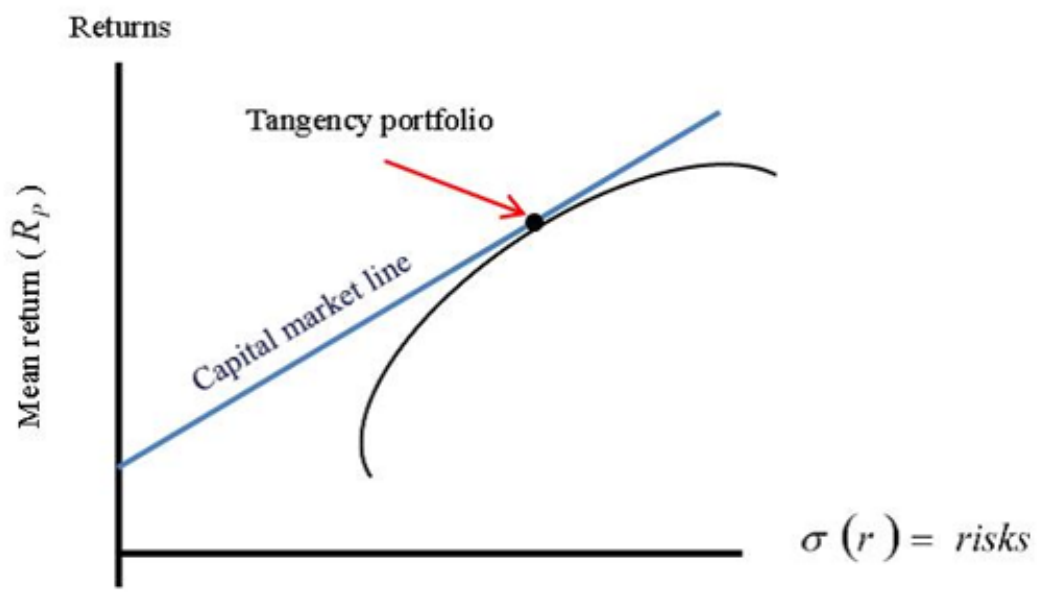

From the superposition $\left(<\Psi|\Psi\rangle=1 \operatorname{or} \omega_{0}^{2}+. .+\omega_{k}^{2}=1\right)$ of quantum mechanics was derived from the wave function based Hermite polynomials in equation (5) must be computed completely for all of data were implemented in this research.

\subsection{The Section of Economic Optimization Models}

\subsubsection{Markowitz Optimization}

When an investment is mentioned, returns and risks are at the center of portfolio theory. Returns are favor, while risks are things that need to be removed (Markowitz, 1952). The most crucial aspect of Markowitz' model is the explanation of the impact on portfolio diversification by the number of securities or indexes within a portfolio and their covariance correlations (Markowitz, 1959), (Megginson, 1996). This approach that leaded him to win the 1990 Nobel Prize in economics allows portfolio managers to reduce the risk of the complete without necessarily losing profits (Figgie, 2004). In financial economics, Modern Portfolio Theory (MPT) based on the Markowitz theory was developed such as Beyhaghim and Hawley (2013), Joshi (2015), and Jones (2015). Following the contribution of Fabozzi et al (2002), MPT is the concept that the selection and construction of investing portfolios are relied on the maximization of expected returns of the portfolio and the simultaneous minimization of investment risks, and this is graphically shown in Figure 4, which is modified from Omisore et al (2012).

To apply MPT for effectively dealing with the research's object, this useful approach is utilized for guiding sustainability discourse under uncertain future scenarios. The environmental question and feasible solution are in the research paper conducted by Matthies et al, (2002). However, the gap needs to be improved is the reliability of means and variances obtained from a distribution. Typically, portfolio allocations are based on the expected mean-variance analysis, which is from the distribution of observed data. In this paper, means and variances are specified by "simulated quantum computing" in the wave function. For mathematical expression, the portfolio expected return (Rp) can be shown as

$$
E\left(R_{p}\right)=x^{T} \mu
$$

Making an application, the expected return $(\mathrm{Rp})$ is applied to stand for the selected variables such as GDP (GDP), energy consumptions (Energy), health expenditures (Healthcare), and CO2 emissions 
(CO2). The example of the application can be found in Matthies et al, (2018). Macroeconomic variables are put into the portfolio by three scenarios such as maximizing values, minimizing volumes, and non-optimal case. The standard deviation for each index is given by

$\sigma_{p}=x^{T} \sum x$

For computing the expected return, it needs a weighted matrix factor described in the matrix as follows:

$x=\left[\begin{array}{l}x_{1} \\ x_{2} \\ \ldots \\ x_{n}\end{array}\right], \mu=\left[\begin{array}{l}\mu_{1} \\ \mu_{2} \\ \ldots \\ \mu_{n}\end{array}\right], \sum=\left[\begin{array}{ccc}\sigma_{11} & \sigma_{12} & \sigma_{13} \\ \sigma_{21} & \sigma_{22} & \sigma_{23} \\ \ldots & \ldots & \ldots \\ \sigma_{k 1} & \sigma_{k 2} & \sigma_{k 3}\end{array}\right]$

From the equation 2, portfolio risks are expressed by the sum of all return covariances, in the form of the portfolio variances, or as the square root of the variance, the standard deviation is therefore described as follows:

$$
\begin{aligned}
& S_{L}=\sqrt{x^{T} \sum x=\sqrt{\sum_{i \in L} \sum_{j \in L} x_{i} x_{j} C O V_{i, j}}} \\
& \text { s.t. } \\
& x^{t}(1)=1 \\
& C O V_{i, j}=\operatorname{Var}_{i} \\
& C O V_{i, j}=k_{i, j} s_{i} s_{j} \\
& x_{i, j} \geq 0 .
\end{aligned}
$$

$\mathrm{S}_{\mathrm{L}}$ is the standard deviation of uncertain portfolio allocation. The portfolio $x i, j$ is given in the terms of correlative investments into the risky assets, which can be alternatively interpreted as a short-run budget allocation. It holds that $\mathrm{xt}(1)=1 . \mathrm{xi}, \mathrm{j}{ }^{3} 0$ implies additional modeling controls. The parameter $\lambda$ is defined as the investor risk aversion measurement, which is used for tracing the whole efficient frontier (Gharakhani \& Sadjadi, 2013). In terms of solving a quadratic programming problem, the Sharpe-optimal portfolio introduced by William Sharpe (Sharpe, 1987) is to solve an optimal capital allocation in existence of the lowest risk asset. It implies that the capital market line (CML) and the Markowitz efficient frontier are optimally tangent at the point that has the highest Sharpe ratio (Khokhlov, 2011). The Sharpe ratio maximization algorithm can be mathematically expressed as the following formula:

$$
R_{s}=\frac{r_{p}-r_{f}}{\sigma_{p}}=\left(r_{p}-r_{f}\right) \sigma_{p}^{-1}=\left[\sum_{i} x_{i} r_{i}-r_{f}\right] \times\left[\sum_{i, j} x_{i} x_{j} \sigma_{i j}\right]^{-0.5}
$$




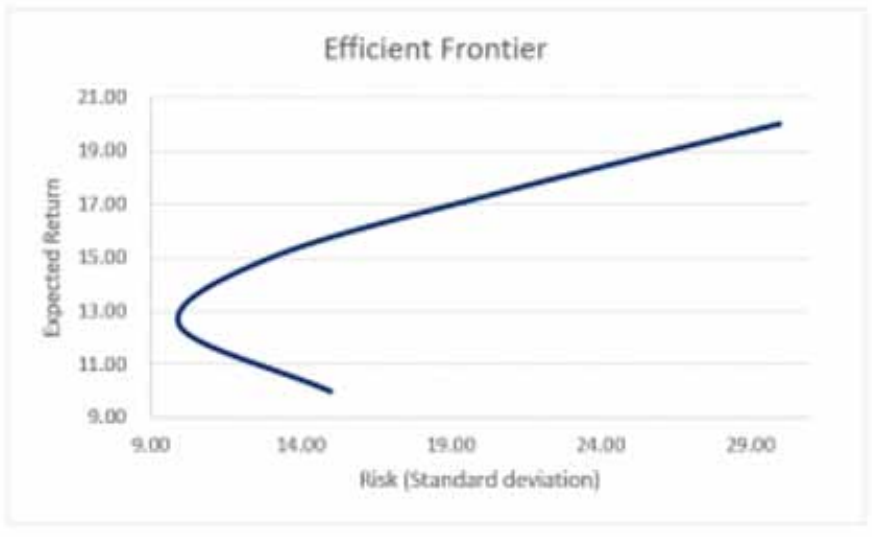

$r_{p}$ denotes the expected portfolio return, and $r_{f}$ is the risk-free rate. $\sigma_{i j}$ is the covariance between returns of $\mathrm{i}$-th and $\mathrm{j}$-th indexes. The derivative of (5) has the same roots when the risk tolerance equals to

$$
r_{t}^{*}=\frac{2 \sigma_{p}^{2}}{r_{p}-r_{f}} .
$$

The highest possible Sharpe ratio when the condition (11) is satisfied, this is the solution for the Sharpe-optimal portfolio without having to resolve a non-liner programming riddle (Khokhlov, 2011).

\subsubsection{The Efficiency Frontier}

The Efficient Frontier is a set of optimal portfolios applied for giving the highest possible expected volume of inserted variables for a given risk level (maximum-return case) or the lowest risk (minimumreturn case). Portfolios below the efficient frontier are sub-optimal, as shown in Figure 5.

The curve is essential in demonstrating how diversification improves the risk or reward profile for each inserted factor. It represents that the relation between risk and return is non-linear. There is a diminishing marginal level to risk; adding more risks does not gain an equal volume. Instead, each additional unit of risk adds a smaller and smaller number of volumes to the applied portfolio.

\section{EMPIRICAL RESULTS}

Singapore, Malaysia, and Thailand are the predominant emerging markets in the south-east pacific continent. Since multicultural activities and ethnic diversity, a divisible fiscal policy for feasible allocations in economic growth, sustainable energy, and public healthcare are the urgently international political consideration. The secondary data using in this paper is the annual macroeconomic series observed from World Bank Database during 2000 to 2017, including GDP, energy consumption (renewable and non-renewable fuels), carbon footprints (carbon dioxide emissions), and healthcare budgets. 


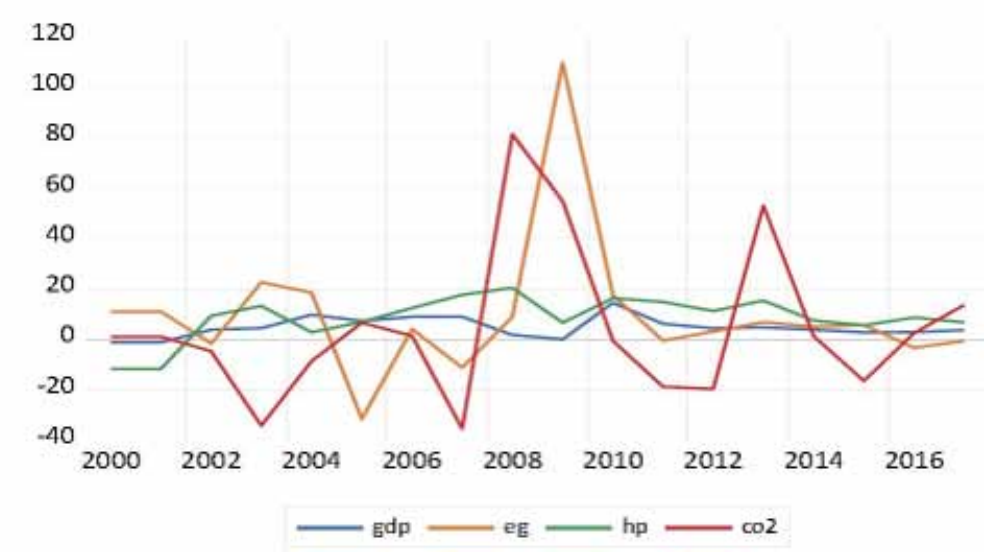

Table 1. The data description of collected variables for Singapore

\begin{tabular}{|c|c|c|c|c|}
\hline & $\begin{array}{r}\text { GDP } \\
(\%)\end{array}$ & $\begin{array}{r}\text { Energy } \\
(\%)\end{array}$ & $\begin{array}{r}\text { Healthcare } \\
(\%)\end{array}$ & $\begin{array}{r}\mathrm{CO} 2 \\
(\%)\end{array}$ \\
\hline Mean & 4.834 & 9.782 & 8.529 & 4.403 \\
\hline Median & 4.182 & 5.411 & 9.079 & 1.092 \\
\hline Maximum & 14.526 & 109.728 & 20.491 & 81.339 \\
\hline Minimum & -1.069 & -31.404 & -11.582 & -35.302 \\
\hline Std.Dev. & 4.009 & 27.723 & 8.688 & 30.518 \\
\hline Skewness & 0.601 & 2.602 & -1.175 & 1.153 \\
\hline Kurtosis & 3.162 & 10.856 & 3.982 & 3.778 \\
\hline Jaque-Bera & 1.102 & 66.603 & 4.868 & 4.445 \\
\hline Probability & 0.576 & 0.000 & 0.087 & 0.108 \\
\hline PP-test & -3.442 & -3.565 & -5.039 & -3.842 \\
\hline Prob. & 0.024 & 0.018 & 0.001 & 0.011 \\
\hline
\end{tabular}

Source: compute

\subsubsection{The Data of Singapore}

Considering into Singapore, Figure 6 represents the fluctuation trends of the three pillars, which are economic growth, environment, and healthcare. The predominant detail indicates energy is evidently unstable. The fluctuated rate is not simply to be absolutely controllable and it is a huge challenge since the main power source in this country is generated by natural gas, indicating $95 \%$ of total energy production (Queka et al, 2018). This fluctuation is also confirmed by the significance (66.6034) of Jarque-Bera normality testing shown in Table.1. The result states the data is not a type of normal 
distribution. On the other hand, the change of healthcare is quite sparse. This national money for public healthcare is on the average $8.529 \%$ per the total national budget.

\subsubsection{The Data of Thailand}

According to Thailand's information displayed in Figure.7, the predominant data shows Thailand could impressively reduce almost $30 \%$ of energy consumption during 2012 to 2016 . This is because of the practical policies on renewable electricity generation, and the $\mathrm{CO} 2$ emissions from power generation expansion plans (PGEPs) are also evaluated (Promjiraprawat \& Limmeechokchai, 2017). Additionally, Table. 2 presents the low average rate of energy consumption per annual is approximately

Figure 7. Descriptive information of observed data for Thailand

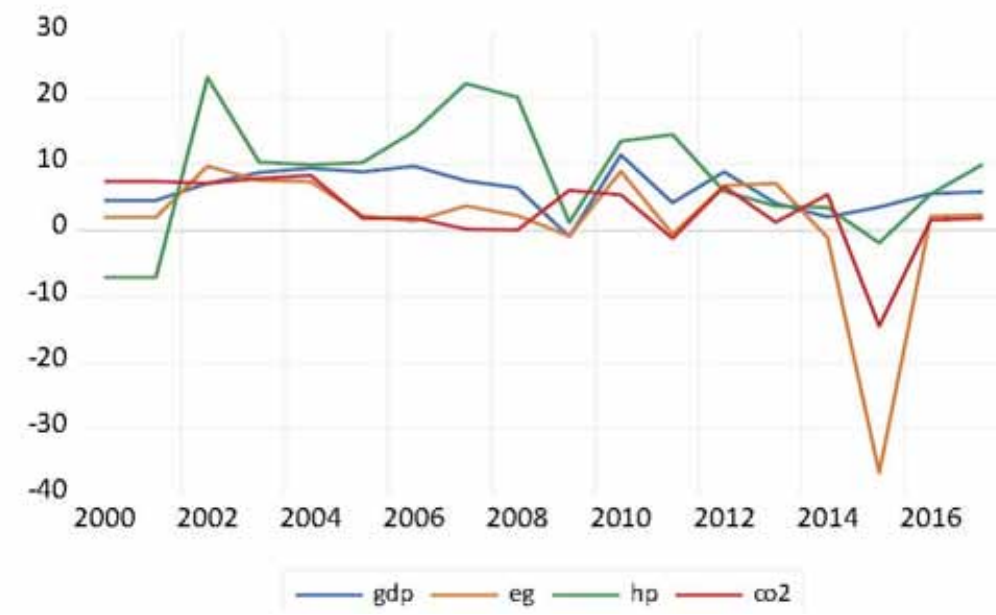

Table 2. The data description of collected variables for Thailand

\begin{tabular}{|c|c|c|c|c|}
\hline & $\begin{array}{r}\text { GDP } \\
(\%)\end{array}$ & $\begin{array}{r}\text { Energy } \\
(\%)\end{array}$ & $\begin{array}{r}\text { Healthcare } \\
(\%)\end{array}$ & $\begin{array}{r}\mathrm{CO2} \\
(\%)\end{array}$ \\
\hline Mean & 6.128 & 1.418 & 8.418 & 2.977 \\
\hline Median & 6.093 & 2.169 & 9.892 & 3.601 \\
\hline Maximum & 11.354 & 9.668 & 23.049 & 8.288 \\
\hline Minimum & -0.997 & -36.668 & -7.142 & -14.522 \\
\hline Std.Dev. & 3.094 & 10.087 & 8.944 & 5.372 \\
\hline Skewness & -0.411 & -3.156 & -0.117 & -1.914 \\
\hline Kurtosis & 2.802 & 12.728 & 2.298 & 7.251 \\
\hline Jaque-Bera & 0.536 & 100.874 & 0.410 & 24.543 \\
\hline Probability & 0.764 & 0.000 & 0.814 & 0.000 \\
\hline PP-test & -4.030 & -3.572 & -3.411 & -3.659 \\
\hline Prob. & 0.008 & 0.019 & 0.025 & 0.016 \\
\hline
\end{tabular}


$1.418 \%$. However, the concerned index is the continuous decrease in public healthcare, which is the average on $8.418 \%$ per year.

\subsubsection{The Data of Malaysia}

Speaking to Malaysia, Figure 8 displays the unpredictable lines of energy usages, $\mathrm{CO} 2$ emissions, and public health expenditures. In particular, the trend of domestic energy consumption is dramatically fluctuated. Stated by Khattak et al (2018), Malaysia is now facing a problem of energy insecurity as ample of resources are needed to sustain the domestic development, especially the issues of price volatility and the reduction in oil production causing the oil business to become unstable. This is backed up by the descriptive details reported by Table 3. Energy consumption is the average on $10.282 \%$ per year, and the $\mathrm{CO} 2$ emission rate is as similar as the increasing level of energy usages, which is the approximate average on $9.354 \%$ per year.

To summarize this section, the data review implies the research gap is the complexity of fluctuated information. It is seemingly suspicious if this data category is promptly assumed to suit to the normal distribution. As a result, quantum mechanics and the wave function are the novel combination to deeply clarify a real distribution for observed data.

\section{EMPIRICAL RESULTS}

\subsection{Quantum Computation in the Wave Function}

As the bridge to link between quantum computing and econometric estimations is the distribution. If the distribution is clarified, means and variances then this can be parametrically observed. Table 4 presents the univeriate distribution for each variable series in each selected country computed by quantum computing based on the wave function. The sets of data series are processing to the portfolio optimization in the next section.

Note: GDP : Gross domestic products

EG : Energy consumption

$\mathrm{CO} 2$ : Carbon dioxide emissions

HP : Public healthcare expenditure

$\mathrm{QM} \mu$ : The mean of the wave distribution computed by quantum mechanics

QM $\sigma$ : The standard error of the wave distribution computed by quantum mechanics

Figure 8. Descriptive information of observed data for Malaysia

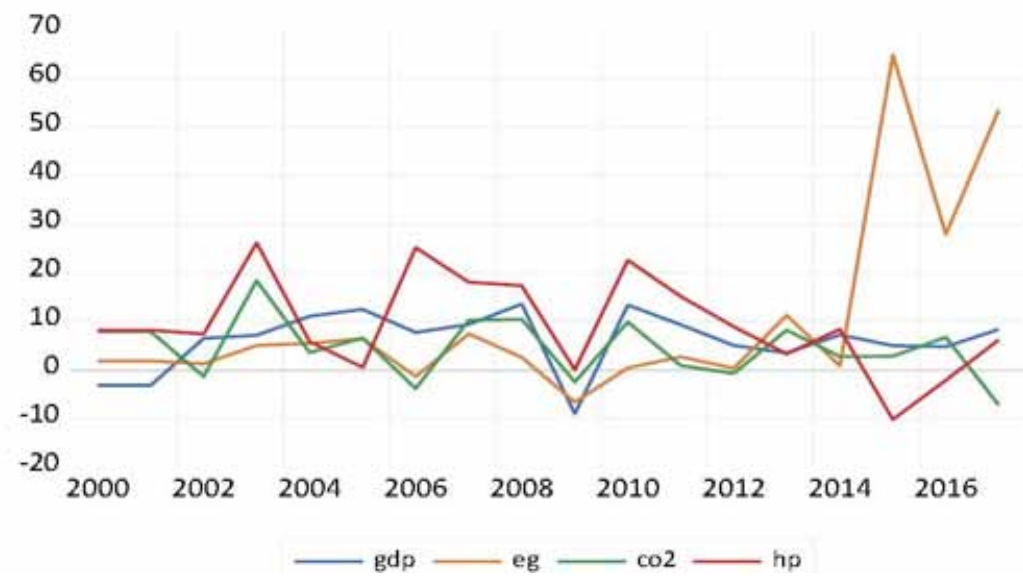


Table 3. The data description of collected variables for Malaysia

\begin{tabular}{|c|c|c|c|c|}
\hline & $\begin{array}{r}\text { GDP } \\
(\%)\end{array}$ & $\begin{array}{r}\text { Energy } \\
(\%)\end{array}$ & $\begin{array}{r}\text { Healthcare } \\
(\%)\end{array}$ & $\begin{array}{r}\mathrm{CO} 2 \\
(\%)\end{array}$ \\
\hline Mean & 6.008 & 10.282 & 4.433 & 9.354 \\
\hline Median & 7.142 & 2.607 & 5.013 & 8.156 \\
\hline Maximum & 13.531 & 64.843 & 18.329 & 26.121 \\
\hline Minimum & -9.081 & -6.692 & -7.317 & -10.261 \\
\hline Std.Dev. & 6.022 & 19.228 & 6.296 & 9.792 \\
\hline Skewness & -1.035 & 2.009 & 0.114 & 0.089 \\
\hline Kurtosis & 3.553 & 5.741 & 2.746 & 2.465 \\
\hline Jaque-Bera & 3.444 & 17.748 & 0.087 & 0.238 \\
\hline Probability & 0.179 & 0.000 & 0.957 & 0.887 \\
\hline PP-test & -4.730 & -15.022 & -6.054 & -3.467 \\
\hline Prob. & 0.002 & 0.001 & 0.000 & 0.023 \\
\hline
\end{tabular}

Source: compute

Table 4. Quantum computing and wave distributions for investigating means, standard errors, and basic Sharpe ratios by country

\begin{tabular}{|c|c|c|c|}
\hline & $\begin{array}{r}\text { QM } \mu \\
(\%)\end{array}$ & $\begin{array}{r}\text { QM } \sigma \\
\quad(\%)\end{array}$ & $\underset{\text { QM }}{\mathbf{Q}} \mu \underset{\mathrm{( \% )}}{\sigma}$ \\
\hline \multicolumn{4}{|c|}{ Singapore } \\
\hline GDP & 0.111 & 0.180 & 0.613 \\
\hline EG & 0.045 & 0.097 & 0.468 \\
\hline $\mathrm{CO} 2$ & 0.081 & 0.160 & 0.508 \\
\hline HP & 0.023 & 0.099 & 0.236 \\
\hline \multicolumn{4}{|c|}{ Thailand } \\
\hline GDP & 2.870 & 7.233 & 0.397 \\
\hline EG & 13.315 & 12.656 & 1.052 \\
\hline $\mathrm{CO} 2$ & 2.292 & 4.048 & 0.566 \\
\hline HP & 2.422 & 5.851 & 0.414 \\
\hline \multicolumn{4}{|c|}{ Malaysia } \\
\hline GDP & 4.230 & 9.729 & 0.435 \\
\hline EG & 9.615 & 15.232 & 0.631 \\
\hline $\mathrm{CO} 2$ & 7.551 & 12.909 & 0.585 \\
\hline HP & 3.670 & 9.664 & 0.380 \\
\hline
\end{tabular}


QM $\mu / \sigma:$ The non-optimal Sharpe ratio

\subsection{Utilizing Portfolio Theory in Feasible Budget Allocations in Singapore, Thailand, and Malaysia}

As following Matthies et al, (2018), the empirical results of this paper comparing with the reference work can be found in the table demonstrating the example of forest performance indices for German tree species contrasting arithmetic and geometric mean as estimates for the expected return (the table 3 , page 18). Additionally, in the appendix, a mean-variance efficient frontier conducts a wide variety of concave utility functions, which stand for characteristics of risk types in the future risk prediction (Fig. A.1, page 35).

\subsubsection{Markowitz Optimization for Short-run Budget Managements}

In terms of the practical optimization for MPT, the short-run budget allocation for Singapore is represented in Table 5. There are scenarios that provide choices for suggesting feasible budgets. The common case is to equally allocate the budget constraint in every sector. $25 \%$ of the total budget is the weight.

Table 5. The short-run budget preparation for Singapore

\begin{tabular}{|c|c|c|c|c|}
\hline \multirow[b]{2}{*}{ Sectors } & \multicolumn{4}{|c|}{ The efficiency budget for Singapore } \\
\hline & Weight & Max Return & Min SD & Max SR \\
\hline $\begin{array}{l}\text { Value constraints for } \\
\text { containing variables }\end{array}$ & Balance & $\begin{array}{l}\text { At } \sigma=0.0518 \\
(\leq 5.18 \%)\end{array}$ & $\begin{array}{c}\text { At } \mu=0.10 \\
(=10 \%)\end{array}$ & Max Sharpe ratio \\
\hline GDP & $25 \%$ & $11 \%$ & $78 \%$ & $17 \%$ \\
\hline EG & $25 \%$ & $40 \%$ & $5 \%$ & $38 \%$ \\
\hline $\mathrm{CO} 2$ & $25 \%$ & $14 \%$ & $10 \%$ & $18 \%$ \\
\hline $\mathrm{HP}$ & $25 \%$ & $34 \%$ & $6 \%$ & $26 \%$ \\
\hline$\sum$ & $100 \%$ & $100 \%$ & $100 \%$ & $100 \%$ \\
\hline$\mu$ & $6.51 \%$ & $5.04 \%$ & $9.86 \%$ & $5.76 \%$ \\
\hline$\sum \rho$ & $6.78 \%$ & $5.18 \%$ & $14.53 \%$ & $5.62 \%$ \\
\hline$\mu / \rho$ & 0.961 & 0.974 & 0.679 & 1.026 \\
\hline
\end{tabular}

Source: compute

The optimization solution in Singapore indicates some noticeable points. In the case of maximum outcomes, the result gives the instruction to increase more energy consumption, which is $40 \%$ increment. However, this suggestion seemingly contradicts the concept of sustainability. The case of the riskless model is also suspicious. The result indicates nearly four of five portions of the national budget is allocated to the image of economic growth. Healthcare is overlooked (6\%). For the scenario that finds the highest Sharpe ratio, the outcome sensibly points two sectors such as energy and public health should be a major parallel consideration, indicating $38 \%$ and $26 \%$, respectively. 
However, economic growth and the concern of pollution emissions should also be recognized, which are $17 \%$ and $18 \%$.

Considering into the portfolio optimization for Thai economy represented in Table 6, maximum and minimum cases numerically show an unbalance allocation. The former is to provide approximately four of five portions for activating policies to reduce pollution and increase the standard of public healthcare. The latter case is the riskless model that the lens of the preparation is enormously set for energy consumption, which is nearly $80 \%$ of available resources. However, the model to find the maximum of Sharpe ratio is different. The result indicates an analogous balance budget, which implies the pollution reduction is the priority (35\%). Energy usages, image of economic growth, and public health supports are also in the major consideration $(25 \%, 21 \%$, and $20 \%)$.

Table 6. The short-run budget preparation for Thailand

\begin{tabular}{|c|c|c|c|c|}
\hline \multirow[b]{2}{*}{ Sectors } & \multicolumn{4}{|c|}{ The efficiency budget for Singapore } \\
\hline & Weight & Max Return & Min SD & Max SR \\
\hline $\begin{array}{l}\text { Value constraints for } \\
\text { containing variables }\end{array}$ & Balance & At $\sigma \leq 3 \%$ & $\begin{array}{c}\text { At } \mu=0.11 \\
(=\mathbf{1 1} \%)\end{array}$ & Max Sharpe ratio \\
\hline GDP & $25 \%$ & $17 \%$ & $5 \%$ & $21 \%$ \\
\hline EG & $25 \%$ & $5 \%$ & $80 \%$ & $25 \%$ \\
\hline $\mathrm{CO} 2$ & $25 \%$ & $59 \%$ & $10 \%$ & $35 \%$ \\
\hline $\mathrm{HP}$ & $25 \%$ & $20 \%$ & $5 \%$ & $20 \%$ \\
\hline$\sum$ & $100 \%$ & $100 \%$ & $100 \%$ & $100 \%$ \\
\hline$\mu$ & $5.225 \%$ & $2.965 \%$ & $11.102 \%$ & $5.149 \%$ \\
\hline$\sum \rho$ & $4.416 \%$ & $2.877 \%$ & $10.275 \%$ & $4.296 \%$ \\
\hline$\mu / \rho$ & 1.183 & 1.031 & 1.081 & 1.199 \\
\hline
\end{tabular}

Source: compute

Speaking to the optimization portfolio for Malaysian economy detailed in Table 7, the cases maximizing outcome and maximum Sharpe ratio are similar. The result indicates Malaysia needs the feasibly balance budget, which the trend of economic growth is priority. The second major issue is pollution reduction, and healthcare is the third consideration. On the other hand, the minimum risk scenario indicates a different suggestion. In this case, energy consumption is defined as an index that safely drives the economy in the short-run period. 
Table 7. The short-run budget preparation for Malaysia

\begin{tabular}{|c|c|c|c|c|}
\hline \multirow[b]{2}{*}{ Sectors } & \multicolumn{4}{|c|}{ The efficiency budget for Singapore } \\
\hline & Weight & Max Return & Min SD & Max SR \\
\hline $\begin{array}{l}\text { Value constraints for } \\
\text { containing variables }\end{array}$ & Balance & At $\sigma \leq 4.771 \%$ & At $\mu=8.743 \%$ & Max Sharpe ratio \\
\hline GDP & $25 \%$ & $36 \%$ & $7 \%$ & $30 \%$ \\
\hline EG & $25 \%$ & $15 \%$ & $80 \%$ & $24 \%$ \\
\hline $\mathrm{CO} 2$ & $25 \%$ & $27 \%$ & $7 \%$ & $25 \%$ \\
\hline HP & $25 \%$ & $23 \%$ & $6 \%$ & $21 \%$ \\
\hline$\sum$ & $100 \%$ & $100 \%$ & $100 \%$ & $100 \%$ \\
\hline$\mu$ & $6.266 \%$ & $5.793 \%$ & $8.743 \%$ & $6.223 \%$ \\
\hline$\sum \rho$ & $4.910 \%$ & $4.771 \%$ & $11.925 \%$ & $4.843 \%$ \\
\hline$\mu / \rho$ & 1.276 & 1.214 & 0.733 & 1.285 \\
\hline
\end{tabular}

Source: compute

To summarize this section, although Singapore, Thailand, and Malaysia are recently showing the capacity to be rapidly grown by an enormous amount of resource usages for aesthetically displaying the image of growth rates, feasible balancing budget constraints are necessary. The quantum Markowitz optimization (QMO) effectively results the three pillars such as economics, environment, and healthcare budgets must be simultaneously a short-run political implementation. Furthermore, to assure the sustainable growth is in a long-term suggestion, the prediction of efficiency frontiers is the useful tool for solving the gap of the research.

\subsection{The Efficiency Frontier for Long-term Budget Managements}

Considering into empirical results of the efficient frontier prediction, the long-term frontier displayed in Figure.9 suggests Singaporean economy is predicted to grow between $3.92 \%$ and $7.58 \%$ during 15 years ahead. Table 8 also reports from the 15 -years frontier prediction.

Figure 9. Markowitz efficiency frontier for the long-run policy in Singapore

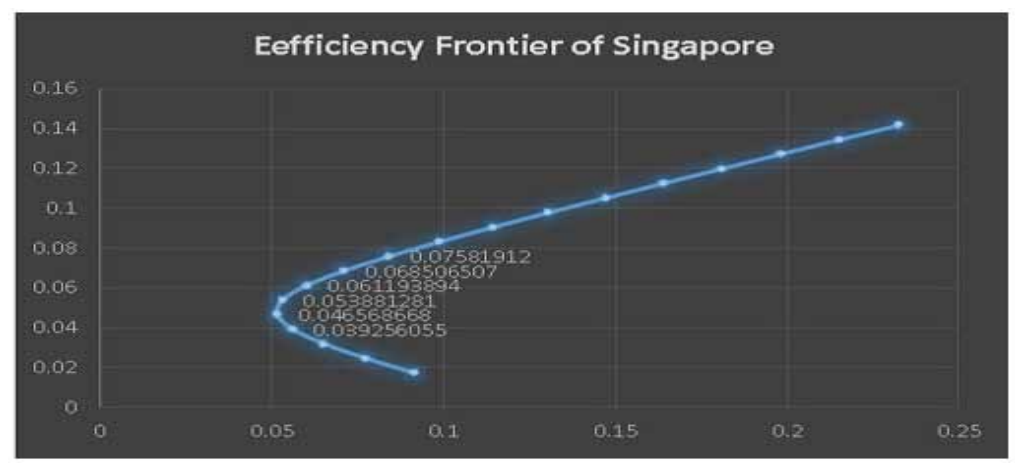


Table 8. The long-run feasible budget allocation for Singapore

\begin{tabular}{|c|c|c|c|c|}
\hline $\begin{array}{c}\text { Option } \\
\text { (i-th year) }\end{array}$ & $\begin{array}{c}\text { The image of } \\
\text { economic growth } \\
\text { (GDP) }\end{array}$ & $\begin{array}{c}\text { Energy } \\
\text { consumption } \\
\text { (EG) }\end{array}$ & CO2 emissions & Public healthcare \\
\hline 10 & $35 \%$ & $36 \%$ & $25 \%$ & $4 \%$ \\
\hline 11 & $28 \%$ & $37 \%$ & $22 \%$ & $22 \%$ \\
\hline 12 & $21 \%$ & $38 \%$ & $13 \%$ & $31 \%$ \\
\hline 13 & $14 \%$ & $38 \%$ & $15 \%$ & $39 \%$ \\
\hline 14 & $7 \%$ & $39 \%$ & $12 \%$ & $48 \%$ \\
\hline 15 & $0.1 \%$ & $40 \%$ & & $20 \%$ \\
\hline
\end{tabular}

Expressly, during the next 10-15 years from the current moment, it is the critical period for considering the consecutive increment of budget preparation in the energy and public health sectors. Particularly, the budget allocated to health securities is suggested to be urgently injected, which is up from $4 \%$ to $48 \%$ during six years. On the other hand, the fiscal allocation is recommended to decrease when considering the policies for improving the impression of economic growth. The budget preparation is vastly reduced from $35 \%$ to $0.1 \%$. Similar to this, the budget for dealing with $\mathrm{CO} 2$ emissions is continuously cut from $25 \%$ to $12 \%$ in six years. The predictive details are also graphically shown in Figure 10.

\section{Figure 10. Predictive trends for long-time sustainable policies for Singapore}

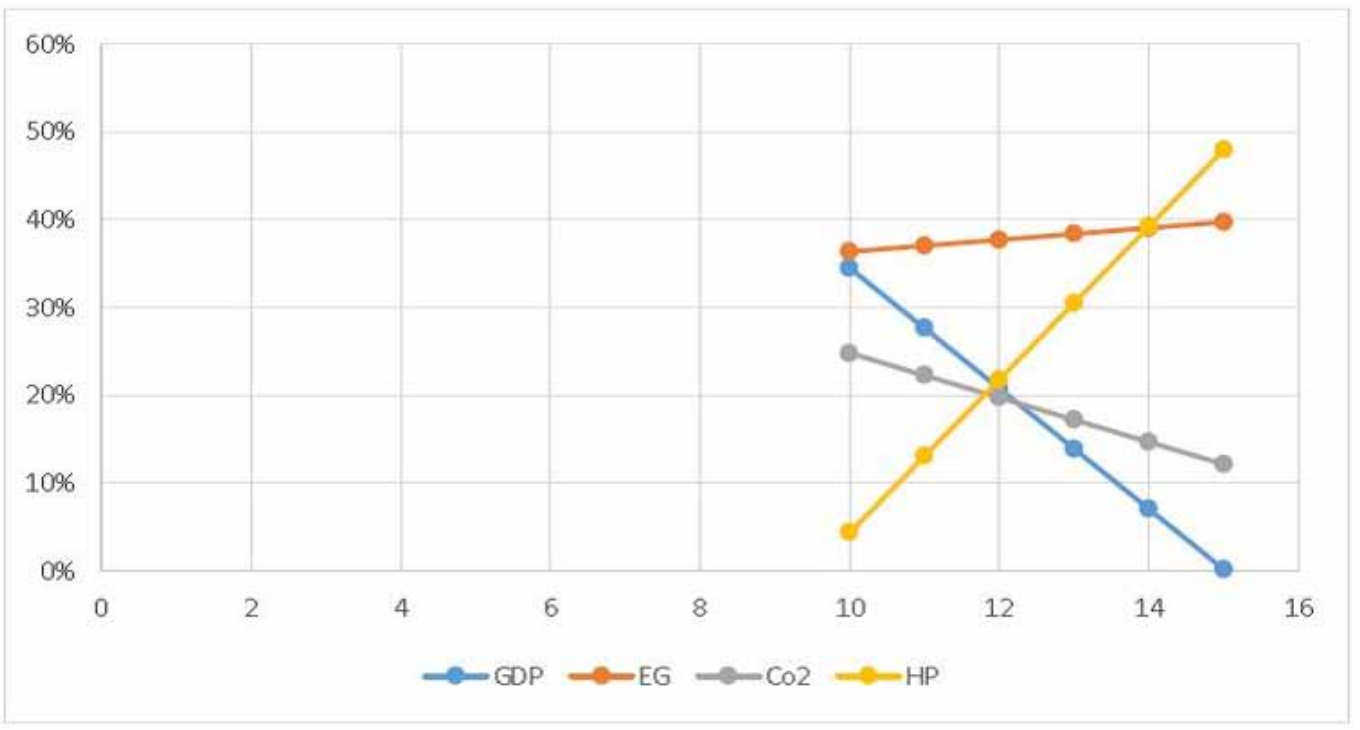

In the case of Thai economy, economic growth rates are predicted to continuously increase between $2.93 \%$ and $8.29 \%$ in the next 13 years (see the detail in Figure.10). However, inside the impressive growth, Table 9 contains the critical point that the image of economic booms and mass energy consumption is being cut, especially the budget to promote mass energy usages are anticipated 


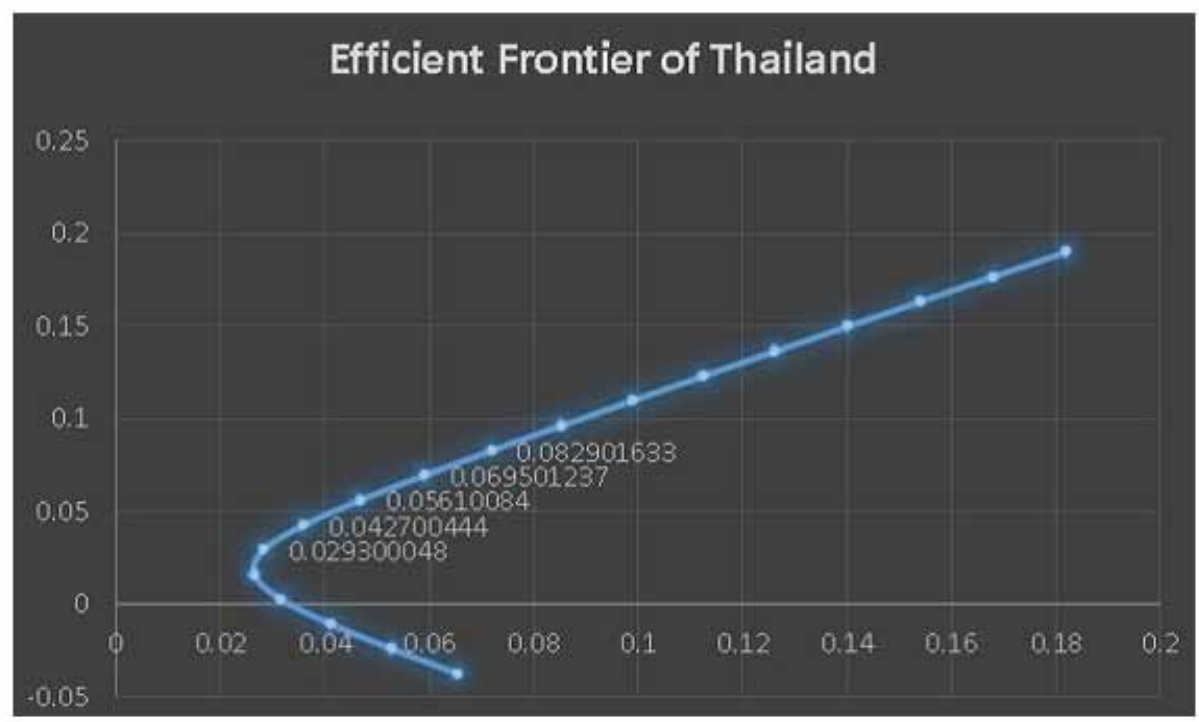

Table 9. The long-run feasible budget allocation for Thailand

\begin{tabular}{|c|c|c|c|c|}
\hline $\begin{array}{c}\text { Option } \\
\text { (i-th year) }\end{array}$ & $\begin{array}{c}\text { The image of } \\
\text { economic growth } \\
\text { (GDP) }\end{array}$ & $\begin{array}{c}\text { Energy } \\
\text { consumption } \\
\text { (EG) }\end{array}$ & CO2 emissions & Public healthcare \\
\hline 9 & $26 \%$ & $53 \%$ & $9 \%$ & $12 \%$ \\
\hline 10 & $23 \%$ & $41 \%$ & $20 \%$ & $15 \%$ \\
\hline 11 & $21 \%$ & $29 \%$ & $31 \%$ & $18 \%$ \\
\hline 12 & $19 \%$ & $17 \%$ & $42 \%$ & $22 \%$ \\
\hline 13 & $17 \%$ & $5 \%$ & $53 \%$ & $25 \%$ \\
\hline
\end{tabular}

Source: compute

to be enormously reduced from $55 \%$ to $5 \%$. Conversely, the optimization portfolio indicates the budget preparation is being moved to launch the policies for recovering the issue of $\mathrm{CO} 2$ emissions, $9 \%$ up to $53 \%$. Also, the budget allocation is predicted to support public healthcare, $12 \%$ up to $25 \%$ during the next 13 years.

Additionally, the details from the table are graphically presented in Figure 12. It deeply shows the budget allocation during five annual periods (the year number 9th to 13th).

Speaking to the empirical result for Malaysian long-term economy, economic growth rates are the forecast outcome to still increase between $4.36 \%$ and $7.49 \%$ in the next 18 years (see the detail in Figure.13). The increasing trend is consistent to the result in Table 10. The efficient allocation for Malaysian economy is to provide for the image of economic growth as well as public health securities, especially the latter is considerably mentioned, which is reported from the enormous increasing proportion of the national budget; $3 \%$ up to $48 \%$ during 7 years. On the other hand, the budget for promoting domestic energy usages and the permission to emit $\mathrm{CO} 2$ is suggested to be cut. In particular, the subsidization for the energy sector is predicted to be reduced from $39 \%$ to $1 \%$. All of information is also graphically detailed in Figure 13. 
International Journal of Asian Business and Information Management Volume $13 \cdot$ Issue 2

Figure 12. The predictive long-term trends for policy recommendations for Thai economy

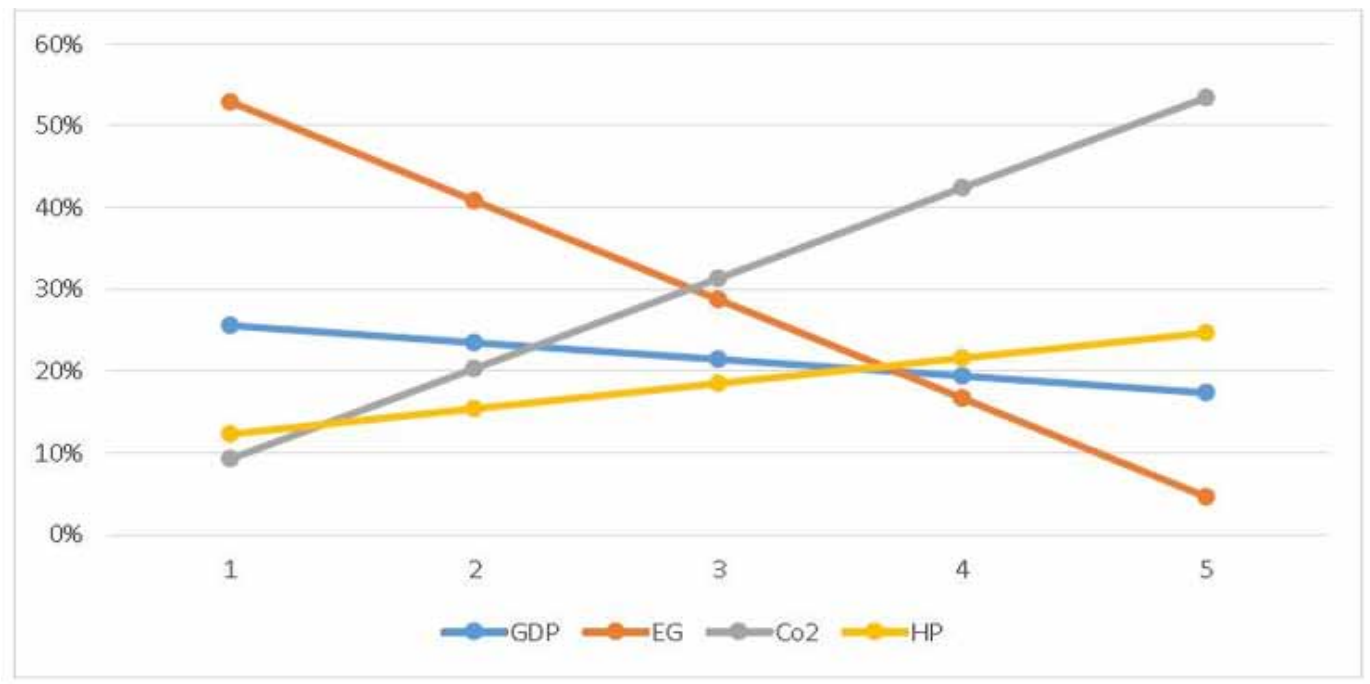

Figure 13. Markowitz efficiency frontier for the long-run policy in Malaysian economy

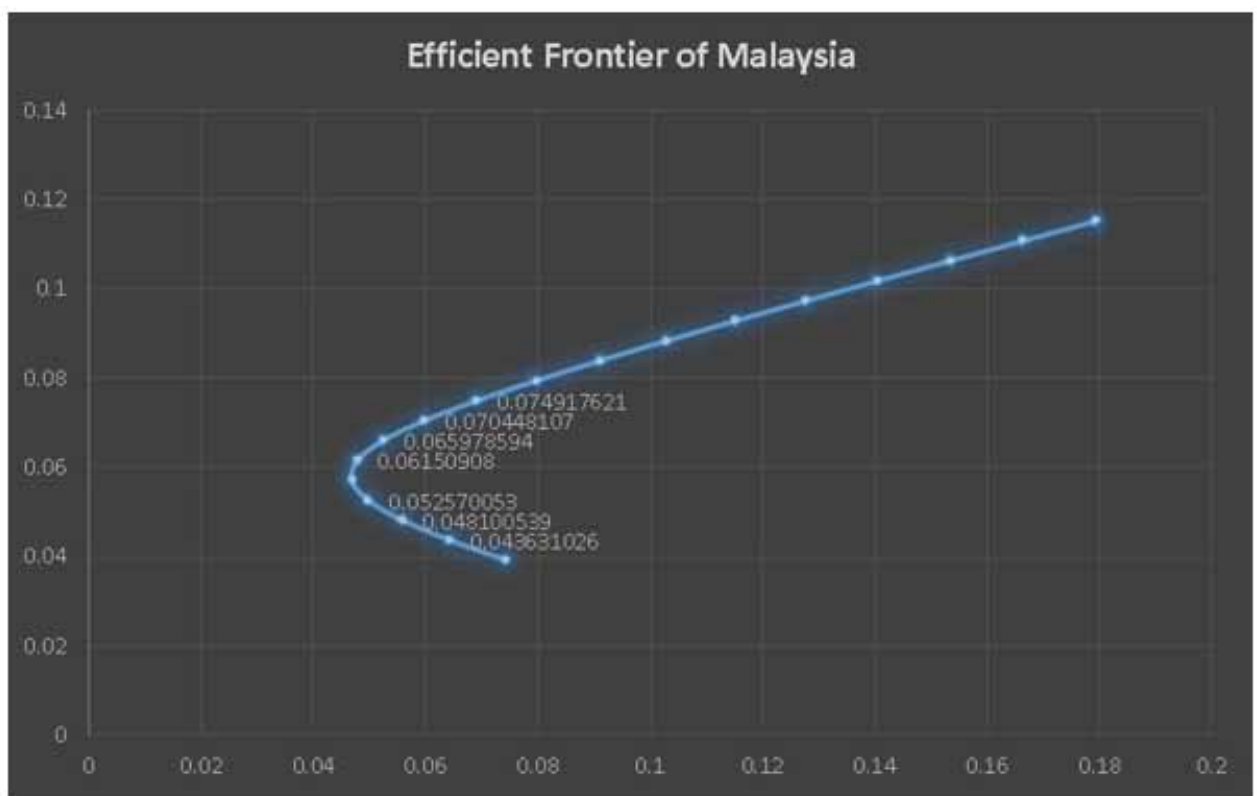


Table 10. The long-run feasible budget allocation for Malaysia

\begin{tabular}{|c|c|c|c|c|}
\hline $\begin{array}{c}\text { Option } \\
\text { (i-th year) }\end{array}$ & $\begin{array}{c}\text { The image of } \\
\text { economic growth } \\
\text { (GDP) }\end{array}$ & $\begin{array}{c}\text { Energy } \\
\text { consumption } \\
\text { (EG) }\end{array}$ & CO2 emissions & Public healthcare \\
\hline 10 & $23 \%$ & $39 \%$ & $35 \%$ & $3 \%$ \\
\hline 11 & $25 \%$ & $34 \%$ & $32 \%$ & $9 \%$ \\
\hline 12 & $28 \%$ & $28 \%$ & $28 \%$ & $22 \%$ \\
\hline 13 & $30 \%$ & $23 \%$ & $25 \%$ & $29 \%$ \\
\hline 14 & $33 \%$ & $17 \%$ & $21 \%$ & $35 \%$ \\
\hline 15 & $35 \%$ & $12 \%$ & $17 \%$ & $42 \%$ \\
\hline 16 & $38 \%$ & $6 \%$ & $14 \%$ & $48 \%$ \\
\hline 17 & $41 \%$ & $1 \%$ & $10 \%$ & 2 \\
\hline
\end{tabular}

Source: compute

Figure 14. The predictive long-term trends for policy recommendations for Malaysian economy

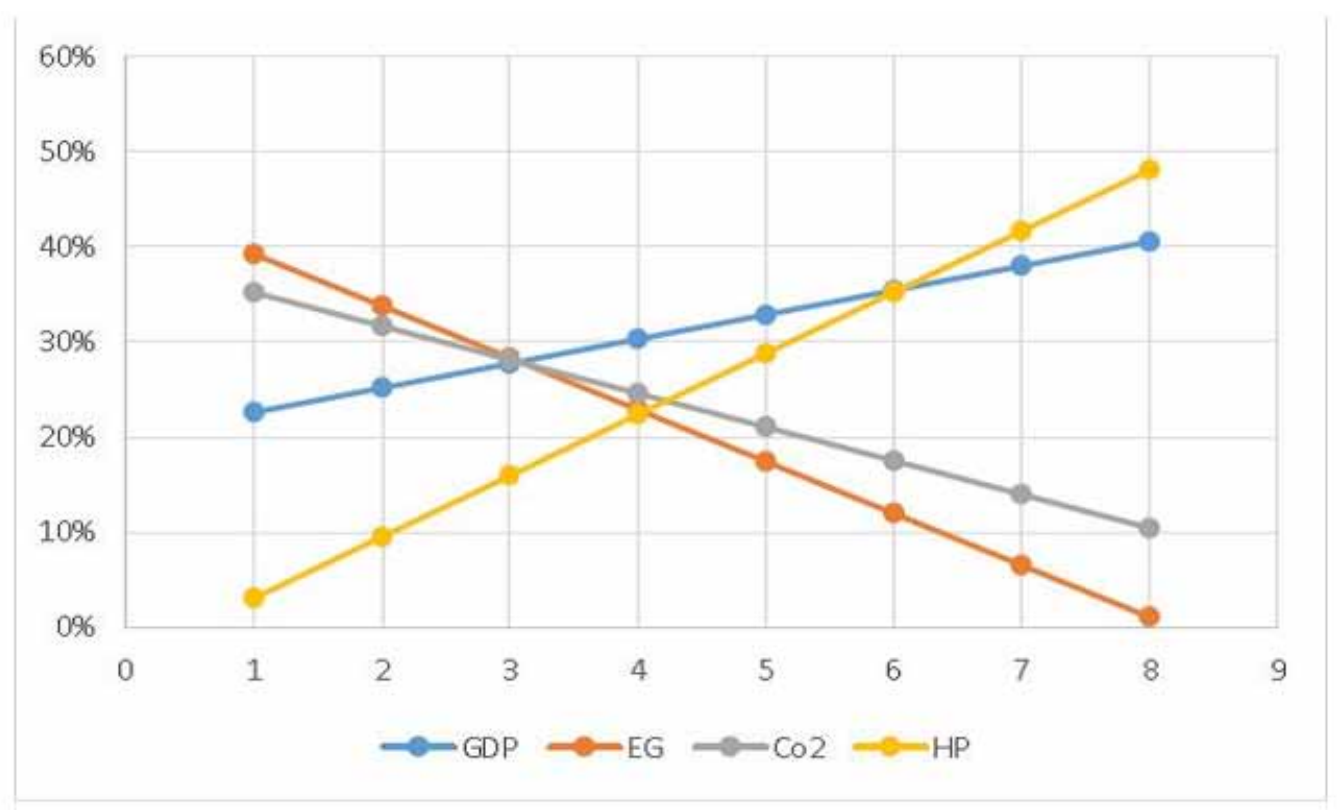

\section{DISCUSSION}

The priority of the research objective is to identify the concept of sustainability with the three pillars of development, including economic expansions, environmental management, and public healthcare. Also, the short-run and long-run policies are being discussed in this section. For the short-run policy or it can be defined as the "visible policy implementation", the national expenditures in Singapore, Thailand, and Malaysia should be the practical decision by considering the optimization allocation. In other words, the budget preparation is suggested to be sustainable balance through using the statistically optimal computation scenario, not arranging by directly political appropriateness. For Singapore, the budget for the energy sector is still necessary. However, it is not for promoting to do 
mass energy usages, but this budget should be practically provided for the project of renewable and sustainable energy. For Thailand, the predominant issue for the short-term policy is the continual micro-project to reduce air pollution (carbon footprints). This policy to locally decrease $\mathrm{CO} 2$ emissions was mentioned by Aroonsrimorakot et al (2013). The practical suggestion is to plant fast growing trees and the option of carbon credits. For Malaysia, the optimal model suggests this country indeed needs the careful balance budget preparation in all sector. With the terms of a multicultural society, Malaysia still remains an ambivalent nationalist project (Aroonsrimorakot et al, 2013).

In terms of long-run policy considerations, the impressive image of economic growth rates is not the highlight for the future. The budget preparation for boosting up the growth should be allocated to the part of public health as many as possible. The contribution of Tak et al (2020) evidently state that the Singapore national center for infectious diseases is facing with the workload technicians and medical staffs to control the majority of COVID-19 cases in the country. This is not only in Singapore, but Malaysia is also confronting with the horrible decease. This seems to be controllable for Thailand. The National Health Security Office (NHSO) has launched the "universal health care" policy since 2002 (Tangcharoensathien et al, 2012). This policy is the healthcare achievement, but policymakers need to pay intensive attention to the money allocation which realigns incentives for providers with the social goals of quality and efficiency of people' lives.

Healthcare is not the only one should be politically and practically considered for the long-term sustainable development. The chronical issue that needs to be continuously maintained is about energy and pollution. For Singapore and Thailand, the sensible policy for environmental management can be defined as an "upside-down project". In other words, the budget to subsidize the activities driven by non-renewable resources should be reduced, and the reduction should be moved to promote a "clean" or "green" project solution and a high-technology research for using alternative fuels in economic activities. After that, the budget allocation will be switched back from the pollution reducing project to the campaign for the use of alternative clean power

However, the budget preparation for the energy sector in Malaysian economy is different. The long-run policy suggestion is a "parallel project". Subsidized money for enhancing domestic fossil fuels productions and usages should be carefully declined step by step. This activation will reflect directly on $\mathrm{CO} 2$ emissions in the country. The reduction of fossil fuel usages by the increment of balance growth and public health funds is the key to open the chance for making sustainable development become substantial in Malaysian economy.

\section{CONCLUSIONS AND POLICY IMPLICATIONS}

This paper is the novel computation in econometrics by applying quantum mechanics and the wave function for searching a real data distribution and portfolio decision approach for solving the problem of feasible budget allocations in ASEAN countries. The core of the computational results is to suggest sensible short-run and long-run policies for developing the scenarios of sustainability, which contains the three crucial pillars such as the image of economic growth, environmental management, and healthcare sector. The proportion provided by the optimization model can be the useful guideline for policy makers who have to critically decide policy for people. This applied research is not only specific for economics or environmental management, but this can be the future research for broadly using to apply and make the critical decision in many topics such as tourism, agricultural science, etc. However, the limitation of the application is the main assumption of the portfolio optimization, which is mostly used for financial researches as the tool for maximizing profits and minimizing risks. In social science, this concept is still elusive to touch the purpose of well-being economics. This is why the empirical result in this paper intensively focuses on the optimal value in Sharpe ratio. For the future exploration, the modification of MPT for optimizing various types of macroeconomic variables will be the interesting aim for the authors. Moreover, the idea of quantum computing will be the main application for distributional data analyses. 


\section{REFERENCES}

Lau, S. K., \& Chan, F. W. (2015). Coronaviruses: Emerging and re-emerging pathogens in humans and animals. Virology Journal, 12(1), 1-3. doi:10.1186/s12985-015-0432-z PMID:26690088

Lau, S. K., Woo, P. C., Li, K. S., Huang, Y., Tsoi, H. W., \& Wong, B. H. (2005). Severe acute respiratory syndrome coronavirus-like virus in Chinese horseshoe bats. Proceedings of the National Academy of Sciences, 102. doi:10.1073/pnas.0506735102

Ge, X. Y., Li, J. L., Yang, X. L., Chmura, A. A., Zhu, G., Epstein, J. H., Mazet, J. K., Hu, B., Zhang, W., Peng, C., Zhang, Y.-J., Luo, C.-M., Tan, B., Wang, N., Zhu, Y., Crameri, G., Zhang, S.-Y., Wang, L.-F., Daszak, P., \& Shi, Z.-L. (2013). Isolation and characterization of a bat SARS-like coronavirus that uses the ACE2 receptor. Nature, 503(7477), 535-538. doi:10.1038/nature12711 PMID:24172901

Hoek, L. V. D., Pyrc, K., Jebbink, M. F., \& Wolthers, K. C. (2004). Identification of a new coronavirus. Nature Medicine, 10(4), 368-373. doi:10.1038/nm1024 PMID:15034574

Daly, H. E. (2004). Allocation, distribution, and scale: Towards an economics that is efficient, just, and sustainable. Ecological Economics, 6(3), 185-193. doi:10.1016/0921-8009(92)90024-M

Gherasim, A., \& Gherasim, D. (2016). The role of distribution in the marketing mix. Economy Transdisciplinarity Cognition, 19, 78-82.

Piketty, T. (2015). Putting distribution back at the center of economics: Reflections on capital in the twenty-first century. The Journal of Economic Perspectives, 29(1), 67-88. doi:10.1257/jep.29.1.67

Wild, C. J. (2015). The concept of distribution. Statistics Education Research Journal, 5, 10-26.

Saghir, A., Hamedani, G. G., Tazeem, S., \& Khadim, A. (2017). Weighted distributions: A brief review, perspective and characterizations. International Journal of Statistics and Probability, 6(3), 109-131. doi:10.5539/ ijsp.v6n3p109

Aharonov, Y., Vaidman, L., \& Anandan, J. (1993). Meaning of the wave function. Physical Review A, 47(6), 4616-4626. doi:10.1103/PhysRevA.47.4616 PMID:9909487

Gao, S. (2013). Interpreting the wave function-What are electrons? And how do they move? Discusiones Filosóficas, 14, 13-23.

Jung, K. (2011). Does the Schrödinger wave function describe a real physical wave? Journal of Physics: Conference Series, 306, 012071. doi:10.1088/1742-6596/306/1/012071

Nguyen, H.T., \& Dong, L.S. (2018). An invitation to quantum econometrics. Studies in Computational Intelligence, 760 .

Dobrovolskiene, N., \& Tamošiunien, R. (2016). Sustainability-oriented financial resource allocation in a project portfolio through multi-criteria decision-making. Sustainability, 8(5), 8. doi:10.3390/su8050485

Fang, M., Tan, K. S., \& Wirjanto, T. S. (2016). Sustainable portfolio management under climate change. Journal of Sustainable Finance \& Investment, 8. Advance online publication. doi:10.1080/20430795.2018.1522583

Scitovsky, T. (1951). The state of welfare economics. Stanford University Press.

Hébert, R. B., \& Ekelund, R. B. (1984). Welfare economics. In Economic Analysis in Historical Perspective. Butterworths Publisher. doi:10.1016/B978-0-408-11430-1.50009-6

Hicks, J. R. (1939). The Foundations of Welfare Economics. Economic Journal (London), 49(196), 696-712. doi: $10.2307 / 2225023$

Ivankina, L., \& Latygovskaya, T. (2015). Modern social welfare in the light of the sustainability model. Procedia: Social and Behavioral Sciences, 166, 111-115. doi:10.1016/j.sbspro.2014.12.493

Tsoulouhas, T. (2014). Pareto optimal allocation. In Wiley Encyclopedia of Management. John Wiley \& Sons, Ltd. Phelan, C., \& Rustichini, A. (2018). A. Pareto efficiency and identity. Theoretical Economics, 13(3), 979-1007. doi:10.3982/TE2719 
Tian, G. (2009). Implementation of Pareto efficient allocations. Journal of Mathematical Economics, 45(1-2), 113-123. doi:10.1016/j.jmateco.2008.07.011

Geraili, A., Sharma, P., Willis, R., \& Romagnoli, J. A. (2013). A simulation and techno-economic optimizationbased methodology to design multi-product lignocellulosic biorefineries. Chemical Engineering Transactions, $32,1183-1188$.

Karshenas, A., \& Haber, D. (2006). Economic optimization of construction project scheduling. Construction Management and Economics, 8(2), 135-146. doi:10.1080/01446199000000012

Zamora-Cristales, R., Sessions, J., Boston, K., \& Murphy, G. (2015). Economic optimization of forest biomass processing and transport in the Pacific Northwest USA. For. Sci., 61(2), 220-234. doi:10.5849/forsci.13-158

Mohajan, H. K. (2017). Optimization models in mathematical economics. Journal of Scientific Achievement, $2,30-42$.

Queka, A., Eea, A., Ngb, A., \& Wahc, T. Y. (2018). Challenges in Environmental Sustainability of renewable energy options in Singapore. Energy Policy, 12, 388-394. doi:10.1016/j.enpol.2018.07.055

Promjiraprawat, K., \& Limmeechokchai, B. (2017). Assessment of Thailand's energy policies and CO2 emissions: Analyses of energy efficiency measures and renewable power generation. Energies, 5(8), 3074-3093. doi:10.3390/en5083074

Khattak, M.A., Keat, L.J., Bapujee, K.A., Hui, T.X., Othman, A.S., Rasid, A.D.A., Shafii, L.F.A., \& Kazi, S. (2018). Global energy security and Malaysian perspective: a review. Progress in Energy and Environment, 6, 1-18.

Markowitz, H. M. (1952). Portfolio selection. The Journal of Finance, 7, 77-91.

Markowitz, H. M. (1959). Portfolio selection. In Efficient Diversification of Investment. Wiley \& Sons.

Megginson, W. (1996). A historical overview of research in finance. The Journal of Finance, 39, 323-346.

Figgie, F. (2004). Bio-folio: Applying portfolio theory to biodiversity. Biodiversity and Conservation, 13(4), 827-849. doi:10.1023/B:BIOC.0000011729.93889.34

Fabozzi, F., Gupta, F., \& Markowitz, H. (2002). The legacy of modern portfolio theory. Journal of Investing, 11(3), 7-22. doi:10.3905/joi.2002.319510

Omisore, I., Yusuf, M., \& Christopher, N. (2012). The modern portfolio theory as an investment decision tool. Journal of Accounting and Taxation, 4(2), 19-28. doi:10.5897/JAT11.036

Matthies, B. D., Jacobsen, J. B., Knoke, T., Paul, C., \& Valsta, L. (2002). Utilising portfolio theory in environmental research - new perspectives and considerations. Journal of Environmental Management, 231, 926-939. doi:10.1016/j.jenvman.2018.10.049 PMID:30602254

Gharakhani, M., \& Sadjadi, S. J. (2013). A fuzzy compromise programming approach for the Black-Litterman portfolio selection model. Decision Science Letters, 2(1), 11-22. doi:10.5267/j.dsl.2012.12.001

Sharpe, W. (1987). An Algorithm for Portfolio Improvement. In Advances in Mathematical Programming and Financial Planning. JAI Press, Inc.

Khokhlov, V. (2011). An algorithm for finding a portfolio with the highest Sharpe ratio. SSRN Electronic Journal, DOI:10.2139/ssrn.1767338

Mangram, M. (2013). A simplified perspective of the Markowitz portfolio theory. Global Journal of Business Research, 7, 59-70.

Müller, H. H. (1989). Modern portfolio theory: Some main results. ASTIN Bulletin, 18(2), 127-145. doi:10.2143/ AST.18.2.2014947

Tay, K., Kamarul, T., Lok, W.Y., Mansor, M., Li, X., \& Wong, J., \& Saw. (2020). A. COVID-19 in Singapore and Malaysia: Rising to the challenges of orthopaedic practice in an evolving pandemic. Malaysian Orthopaedic Journal, 14. PMID:32313613

Aroonsrimorakot, S., Yuwaree, C., Arunlertaree, C., Hutajareorn, R., \& Buadit, T. (2013). Carbon footprint of faculty of environment and resource studies. APCBEE Procedia, 5, 175-180. doi:10.1016/j.apcbee.2013.05.031 
Yusof, N., \& Zeiny, E. (2018). Reconstructing multiculturalism in Malaysia through visual culture. Mediterranean Journal of Social Sciences, 8(4-1), 99-105. doi:10.2478/mjss-2018-0078

Tangcharoensathien, V., Suphanchaimat, R., Thammatacharee, N., \& Patcharanarumol, W. (2012). Thailand's Universal Health Coverage Scheme. Economic and Political Weekly, 47, 53-57.

Alvarez, S., Larkin, S. L., \& Ropicki, A. (2017). Optimizing provision of ecosystem services using modern portfolio theory. Ecosystem Services, 27, 25-37. doi:10.1016/j.ecoser.2017.07.016

Matthies, B. D., Jacobsen, J. B., Knoke, T., Paul, C., \& Valsta, L. (2019). Utilising portfolio theory in environmental research - New perspectives and considerations. Ecosystem Services, 231, 926-939. PMID:30602254

Tóth, M., Holúbek, I., \& Seren`céš, R. (2016). Applying Markowitz portfolio theory to measure the systematic risk in agriculture. In International Scientific Days 2016. The Agri-Food Value Chain: Challenges for Natural Resources Management and Society. Slovak University of Agriculture in Nitra.

Ando, A. W., Fraterrigo, J., Guntenspergen, G., Howlader, A., Mallory, M., Olker, J. H., \& Stickley, S. (2018). When portfolio theory can help environmental investment planning to reduce climate risk to future environmental outcomes and when it cannot. Conservation Letters, 12596(6), 1-10. doi:10.1111/conl.12596

Einstein, A. (1905). Ist die Trägheit eines Körpers von seinem Energieinhalt Abhänging? Annalen der Physik, 18(13), 639-664. doi:10.1002/andp.19053231314

De-Broglie, L. (1924). Recherches sur la théorie des quanta [Researches on the quantum theory]. Ann. Phys., 3, 22.

Thompson, M. B. (2018). Wave function representation of real distributions. R package version 1.0.0. https:// cran.r-project.org/package= wavefunction

Schrödinger, E. (1926). An undulatory theory of the mechanics of atoms and molecules. Physical Review, 28(6), 1049-1070. doi:10.1103/PhysRev.28.1049

Beyhaghim, M., \& Hawley, J. P. (2013). Modern portfolio theory and risk management: Assumptions and unintended consequences. Journal of Sustainable Finance \& Investment, 3(1), 17-37. doi:10.1080/20430795 .2012 .738600

Joshi, H. S. (2015). Practical application of modern portfolio theory in context to asset allocation by investing in negatively correlated assets reduces your risk. International Journal of Research in Humanities \& Social Sciences, 3, 1-6.

Jones, C. K. (2015). Modern portfolio theory, digital portfolio theory and intertemporal portfolio choice. American Journal of Industrial and Business Management, 7(07), 833-854. doi:10.4236/ajibm.2017.77059

Merton, R. C. (1972). An analytical derivation of the efficient frontier. Journal of Financial and Quantitative Analysis, 7(4), 1851-1872. doi:10.2307/2329621

Bodnar, T., \& Schmid, W. (2009). Econometrical analysis of the sample efficient frontier. European Journal of Finance, 15(3), 317-335. doi:10.1080/13518470802423478

Patra, S. (2019). A Quantum framework for economic science: new directions. Economics Discussion Paper No. 2019-20. Kiel Institute for the World Economy. http://www.economics-ejournal.org/economics/ discussionpapers/2019-20

OrrellD. (2020). A quantum walk model of financial options. In A Quantum Walk Model of Financial Options. An Applied Mathematics Introduction. Panda Ohana Publishing. https://ssrn.com/abstract=351248110.2139/ ssrn.3512481

Orrell, D. (2020). The value of value: A quantum approach to economics, security and international relations. Security Dialogue, 51(5), 482-498. doi:10.1177/0967010620901910

Nanni, P. (2016). "Well-Being" before "Welfare society": Historical realities and language. Agriculture and Agricultural Science Procedia, 8, 755-761. doi:10.1016/j.aaspro.2016.02.062

Hernawan, S., Salam, R., Haerul, M., \& Suprianto, M. (2017). Regional council role in the welfare society program. Advances in Social Science, Education and Humanities Research, 149, 31-33. doi:10.2991/icest-17.2017.11 
Koo, J., Choi, Y.J., \& Park, I. (2019). Innovation and welfare: the marriage of an unlikely couple. Social Investment in the Knowledge-Based Economy: New Policies and Politics, 39(2).

Dold, M., \& Krieger, T. (2017). Competition or conflict? Beyond traditional ordo-liberalism. Diskussionsbeiträge, No. 2017-02, Albert-Ludwigs-Universität Freiburg, Wilfried-Guth-Stiftungsprofessur für Ordnungs und Wettbewerbspolitik, Freiburg.

Mendolicchio, C., \& Pietra, T. (2018). Full and constrained Pareto optimality with incomplete financial markets. IAB Discussion Paper Articles on labour market issues 22/2018.

Stuarta, R. M., Haghparast-Bidgolic, H., Panovska-Griffithsd, J., Grobickic, L., Skordisc, J., Kerr, C. C., Kedzioraa, D. J., Martin-Hughesa, R., Kellya, S. L., \& Wilsona, D. P. (2019). Applying the 'no-one worse off' criterion to design Pareto efficient HIV responses in Sudan and Togo. AIDS (London, England), 33(7), 1247-1252. doi:10.1097/QAD.0000000000002155 PMID:30664007

Biró, P., \& Gudmundsson, J. (2020). Complexity offinding Pareto-efficient allocations of highest welfare. CERSIE Working Papers No. CERS-IE WP - 2020/16. Institute of Economics, Centre for Economic and Regional Studies, Budapest.

Mineyama, T., Hirata, W., \& Nishizaki, K. (2019). Inflation and social welfare in a new Keynesian model: the case of Japan and the U.S. Bank of Japan Working Paper Series No.19-E-10. Bank of Japan.

Matthies, B. D., Jacobsen, J. B., Knoke, T., Paul, C., \& Valsta, L. (2018). Utilising portfolio theory in environmental research - New perspectives and considerations. Journal of Environmental Management, 231, 926-939. doi:10.1016/j.jenvman.2018.10.049 PMID:30602254 